\title{
Assessing vehicle restraint systems on horizontal curves
}

\author{
Marcin Budzyński ${ }^{1, *}$, and Dawid Bruski ${ }^{2}$ \\ ${ }^{1}$ Gdańsk University of Technology, Faculty of Civil and Environmental Engineering, Highway and \\ Transportation Engineering Department, ul. Gabriela Narutowicza 11/12, 80-233 Gdańsk, Poland \\ ${ }^{2}$ Gdańsk University of Technology, Faculty of Civil and Environmental Engineering, Department of \\ Mechanics of Materials and Structures, ul. Gabriela Narutowicza 11/12, 80-233 Gdańsk, Poland
}

\begin{abstract}
Horizontal curves, an element of road infrastructure, have a statistically high number of accidents. Considering that horizontal curves in the last ten years have had app. $10 \%$ of all road accidents representing app. $14 \%$ of all fatalities on Polish roads, the issue is serious and requires more research and proper road safety treatments. Data for $2007-2016$ show that in the case of accidents on horizontal curves app. $45 \%$ of the fatalities happened as a result of crashing into roadside obstacles such as signs and first of all trees. This shows that horizontal curves require road safety equipment, and specifically, safety barriers. Key to this is using the right equipment and the right parameters. To achieve that, full-scale crash tests should be conducted to be followed by numerical tests. The article will present a synthesis of the available research conducted in Poland and abroad. An assessment will be made of four crash tests of TB32 with barriers that have a steel and cable guardrail. They are the outcome of the RID 3A "Road safety equipment" project called RoSE. Building on these tests, numerical test results will be presented.
\end{abstract}

\section{Introduction}

Key to ensuring that existing and planned road infrastructure is managed effectively and efficiently is understanding the risks to road safety on a road network, a road section or junction. Decisions must be supported with data about the current level of road safety and how it may change in the years to come $[1,2]$. Treatments can also include road restraint systems.

Historical accident and traffic data can be used to calculate risk measures which can help to establish the level of road safety on a specific element of the road. As a result, risk sections can be identified where injuries and fatalities are likely to be high $[3,4]$. This helps to apply road safety treatments effectively. A combination of road safety knowledge and road safety models will help to identify the costs and benefits of road safety treatments (such as additional lanes, speed enforcement, safety barriers, improvement of horizontal curves, etc.) $[3,5]$. One of the groups of variables included in road safety measure models is

\footnotetext{
* Corresponding author: mbudz@.pg.edu.pl
} 
related to a road's vertical alignment, and specifically the occurrence of horizontal curves. They include:

- a division into straight sections and sections with curves [6],

- length of straight road sections [7],

- density of horizontal curves/length of curve per kilometre of road/presence of curves with big turning angles [8],

- route turning angle [9],

- density/number of vertical curves [10],

- occurrence of transition curve [11],

- radius/length of horizontal curve [12],

road curvature $[13,14]$.

Because the necessary data are difficult to obtain, Poland's road safety measure models do not include horizontal curve parameters. While the variables in many of the models include road geometry parameters, it is not clear how they affect road safety [15]. Given Poland's very high share of run-off-road fatalities, horizontal curve parameters are particularly important. With an estimated $40 \%$ of people killed in run-off-road accidents occurring on and around horizontal curves, it is clear how serious the problem is, i.e. a combination of horizontal curves with hazardous roadsides. Horizontal curves and their parameters have a strong effect on road safety [16-19]. Horizontal curves are strongly correlated to speed and visibility [20]. The characteristics of speed profiles and the profile and curvature of vehicle trajectory on curves in vertical alignment are affected by the road's qualitative features such as radius, turning angle, width of roadway and roadway conditions caused by the weather (dry and wet conditions) [21]. Visibility is curbed when horizontal curve areas include junctions, elements of interchanges (ramps), pedestrian crossings, etc. There may be additional hazards when demand for overtaking and speed dispersion are high. In conditions of limited visibility, head-on collisions are a real risk.

Because run-off-road accidents are a frequent occurrence on horizontal curves, it is important to use the right road safety equipment, especially safety barriers, by looking at the location, type (containment level, working width) and kind (cable, steel, concrete).

To help with selecting road safety equipment, numerical crash tests offer a good tool and complement the results of crash tests on test sites. There are a number of papers on horizontal curve numerical tests. The paper [22] gives a comparison of experimental and numerical results of the TB32 numerical crash test (a $1500 \mathrm{~kg}$ vehicle, at $110 \mathrm{~km} / \mathrm{h}$, crash angle $20^{\circ}$ ) involving an SP-05/2 barrier on a concave horizontal curve at radius $\mathrm{R}=150 \mathrm{~m}$ in four variants of varying approach speeds and a barrier. The research [23] discusses the numerical results of a crash involving a light passenger car and a steel barrier mounted on a concave curve. Paper [24] covers a simulated crash of a vehicle into a concrete concave barrier on a horizontal curve. There is an extensive study of crash tests of the N2-W4-A steel barrier on a curve presented in [25]. The report [26] includes information about cable barriers used on horizontal curves. The paper [15] presents the effects of numerical tests for bridge concrete barriers with some of them located on horizontal curves.

\section{Statistical data}

In Poland between 2007 and 2016 there were 46,800 accidents on horizontal curves representing about $15 \%$ of all accidents in Poland. The accidents involved 65,900 injuries (13\% of all injuries) and 6,400 people killed (16\% of all fatalities). In 2016 there were nearly 4,000 accidents on curves (12\% of all accidents) involving more than 5,000 injuries ( $13 \%$ of all injuries) and more than 500 people killed (15\% of all fatalities). The data show that safety on horizontal curves is a serious problem and that efforts must be taken to improve road user safety. 
Analysis of the types of accidents on horizontal curves $(2012$ - 2016) showed that roadside-related accidents represent $29 \%$ of all accidents on curves and involve $27 \%$ of all injuries on curves and $38 \%$ of all fatalities which occur on this element of road infrastructure. The details are presented in Table xx. Roadside accidents and their casualties are highlighted.

Table 1. Types of road accidents on horizontal curves 2012-2016.

\begin{tabular}{|l|r|r|r|r|}
\hline \multicolumn{1}{|c|}{ Type of road incident } & \multicolumn{1}{c|}{ Accidents } & \multicolumn{1}{c|}{ Injuries } & \multicolumn{1}{c|}{$\begin{array}{c}\text { Serious } \\
\text { injuries }\end{array}$} & \multicolumn{1}{c|}{ Fatalities } \\
\hline Other & 2247 & 2961 & 761 & 126 \\
\hline Hitting a safety barrier & 642 & 808 & 199 & 72 \\
\hline Hitting a tree & 3176 & 4040 & 1409 & 712 \\
\hline Hitting a pedestrian & 1548 & 1476 & 555 & 251 \\
\hline Hitting a pole, sign & 864 & 1080 & 306 & 99 \\
\hline Vehicle roll-over on the road & 3229 & 4057 & 1013 & 240 \\
\hline Vehicle roll-over on the roadside & 1169 & 1538 & 455 & 112 \\
\hline Vehicle side crash & 2625 & 3530 & 916 & 282 \\
\hline Vehicle head-on collision & 4276 & 7474 & 2283 & 669 \\
\hline Vehicle rear crash & 708 & 924 & 179 & 60 \\
\hline Total & $\mathbf{2 0 4 8 4}$ & $\mathbf{2 7 8 8 8}$ & $\mathbf{8 0 7 6}$ & $\mathbf{2 6 2 3}$ \\
\hline
\end{tabular}

The share of accidents involving hitting a safety barrier on horizontal curves represents $3 \%$ of all accidents on curves. As regards injuries and fatalities, they account for $3 \%$ of all injuries and fatalities respectively. This is not to say that safety barriers on horizontal curves do not represent a safety issue. Instead the data show that too few sections with horizontal curves have safety barriers. The severity of run-off-road accidents on horizontal curves and hitting a tree - 22 fatalities per 100 accidents - compared to the severity of accidents involving hitting a safety barrier (11 fatalities per 100 accidents) confirms how critical it is to secure this element of the road network. Another issue that requires new regulations and guidelines is the introduction of mandatory safety zones.

\section{Methodology}

A series of numerical simulations of crash tests involving cable and steel barriers on horizontal convex curves were conducted for the purposes of this work. Crash test parameters correspond to the those of the standard TB32 test [27,28] where a $1500 \mathrm{~kg}$ passenger car hits a barrier at $110 \mathrm{~km} / \mathrm{h}$ at an angle of $20^{\circ}$. It departs from the standard because it applies to barriers on horizontal curves (standards [27,28] only apply to tests of straight sections of safety barriers). The computations were made in LS-DYNA's [29] Method of Finite Elements environment (MES) (MPP double precision R8.1.0) on Tryton super computer managed by the Academic Computer Centre (CI TASK) in Gdańsk, Poland. To perform the integration of nonlinear equation of motion, LS-DYNA code uses explicit scheme of central difference method.

Cable barrier (fig. 1a) consists of three wire ropes mounted to posts using hooks. The wire ropes are pre-tensed. The barrier's straight section is $64.1 \mathrm{~m}$ long. Posts are spaced every $2 \mathrm{~m}$. The barrier system is $0.75 \mathrm{~m}$ high. 
Steel barrier is presented in fig. 1b. Its guardrail is mounted to posts using brackets. The barrier's straight section is $74.3 \mathrm{~m}$ long. The posts are spaced every $2 \mathrm{~m}$. The barrier system is $0.71 \mathrm{~m}$ high.

Cylinder-shaped bases are used to model the ground below the barrier posts. The ground is a continuum with a given shear modulus. As regards its spatial approximation, it is modelled from three dimensional finite elements. In addition, the contact conditions between the barrier's posts and the ground is used in the model. Boundary conditions were also added, i.e. all nodes are fixed on the lateral surface and the cylinder's lower base.

The barriers' numerical model was enhanced with a model of a BMW vehicle (fig. 1c) at 1.5 tonnes. The BMW vehicle model was developed by Transpolis (formerly LIER), a French crash-test house and digital simulation office for road safety equipment. Following some necessary modification, the model now meets the needs of steel and cable barrier simulations (e.g. modified discretisation of selected parts, a different way to fix the car's bonnet).

The calculations were made in two groups: for a cable barrier and steel barrier. Each of the groups comprises 4 simulations. In three simulations the radius of the curve with the barrier changes. The fourth simulation looks at a barrier on a straight section $(\mathrm{R}=\infty)$. The results of the simulation are used to compare the effects of curve radius on the barrier's functional features. Fig. 2 shows the numerical models for the cases.

a)

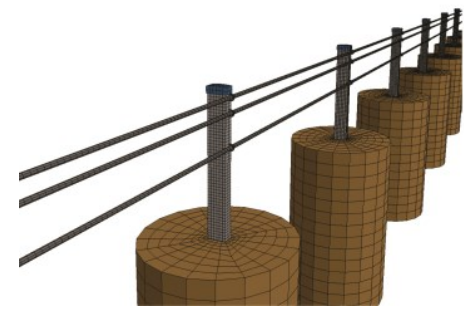

b)

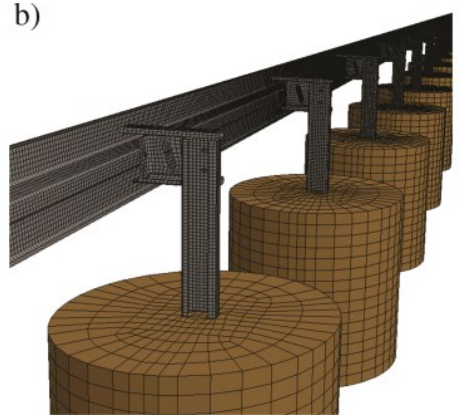

c)

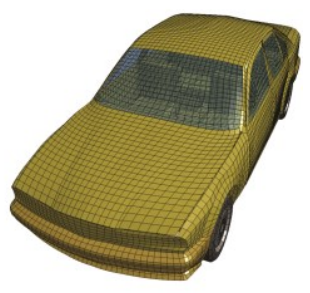

Fig. 1. Discretization of the model, a) cable barrier, b) steel barrier, c) a BMW car.

a) Cable barrier
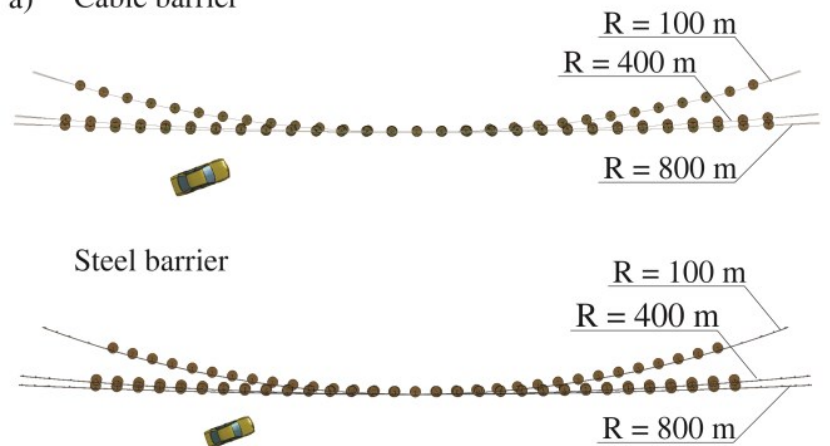

b) Cable barrier

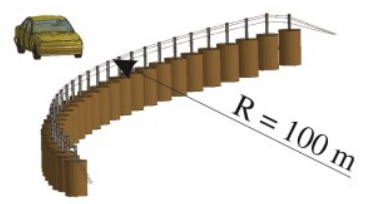

Steel barrier

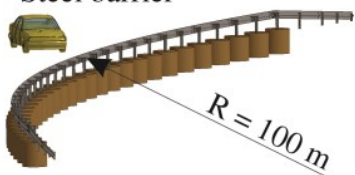

Fig. 2. Numerical models of cable and steel barriers, a) top views, b) general view of the cable barrier (top) and steel barrier (bottom) on a horizontal curve and a radius of $100 \mathrm{~m}$.

\section{Discussion of the results}

Table 2 and Table 3 show ASI, THIV and $\mathrm{W}_{\mathrm{N}}$ (see: [27,28]) obtained from the numerical tests for cable and steel barriers on horizontal curves. The results suggest that for the cases 
under analysis, both for the cable and steel barriers, impact severity indices (ASI and THIV) do not change significantly depending on the horizontal curve radius. The values meet crash intensity A according to standard [28] - ASI $\leq 1.0$ and THIV $\leq 33 \mathrm{~km} / \mathrm{h}$. Please note, however, that a barrier on a convex horizontal curve has a substantial effect on barrier deformation expressed with working width $\mathrm{W}_{\mathrm{N}}$. If installed on a convex curve, the barrier will feature a higher working width. This may be a particular road safety hazard, if there are obstacles such as bridge supports, gantry pole or trees behind the barrier within a distance which exceeds the impact zone of the working width as designated in a real crash test described in the standard (i.e. for a straight barrier section). Working width increase is insignificant for radii $\mathrm{R}=400 \mathrm{~m}(10 \%$ for a cable barrier, $5 \%$ for a steel barrier $)$ and $\mathrm{R}=$

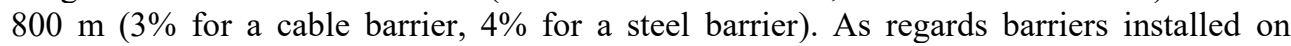
a curve $\mathrm{R}=100 \mathrm{~m}$ working width increases significantly. For a steel barrier the increase is $18 \%$ and $62 \%$ for a cable barrier. The reason for the increase in the case of cable barriers is that the wire rope strength drops as a result of the wire ropes aligning themselves along the curve's chord rather than along the curve as they detach from the posts. A similar conclusion regarding cable barriers can be found in [26]. It is emphasized here that despite the significant percentage increase of the working width of the cable barrier, which was installed on the curve of a $100 \mathrm{~km}$ radius, the working width increases only by $63 \mathrm{~cm}$ and the barrier itself correctly captured and redirected the vehicle, thus fulfilling its role. Fig. 3 shows a comparison of the tests for barriers on a curve $\mathrm{R}=100 \mathrm{~m}$ and a straight section. Please note, however, that as regards cable barriers, when curve radii are below $300 \mathrm{~m}$ number of posts should increase so that the barrier's working width does not increase significantly. In the numerical tests under consideration, post spacing is constant and the results are treated as purely theoretical and designed for scientific applications only.

Table 2. Results of numerical simulations for a steel barrier on a concave horizontal curve.

\begin{tabular}{|c|c|c|c|c|}
\hline Test & Radius, $\mathbf{m}$ & ASI, - & THIV, $\mathbf{k m} / \mathbf{h}$ & $\mathbf{W}_{\mathbf{N}}, \mathbf{m}$ \\
\hline CB_100 & $\mathrm{R}=100$ & 0.52 & 20.4 & 1.91 \\
\hline CB_400 & $\mathrm{R}=400$ & 0.59 & 20.6 & 1.30 \\
\hline CB_800 & $\mathrm{R}=800$ & 0.57 & 21.2 & 1.21 \\
\hline CB_base test & $\mathrm{R}=\infty$ & 0.60 & 20.8 & 1.18 \\
\hline
\end{tabular}

Table 3. Results of numerical simulations for a steel barrier on a convex horizontal curve.

\begin{tabular}{|c|c|c|c|c|}
\hline Test & Radius, $\mathbf{m}$ & ASI, & THIV, $\mathbf{k m} / \mathbf{h}$ & $\mathbf{W}_{\mathbf{N}}, \mathbf{m}$ \\
\hline SB_100 & $\mathrm{R}=100$ & 0.60 & 25.3 & 1.64 \\
\hline SB_400 & $\mathrm{R}=400$ & 0.62 & 22.3 & 1.46 \\
\hline SB_800 & $\mathrm{R}=800$ & 0.57 & 22.1 & 1.44 \\
\hline SB_base test & $\mathrm{R}=\infty$ & 0.64 & 21.1 & 1.39 \\
\hline
\end{tabular}




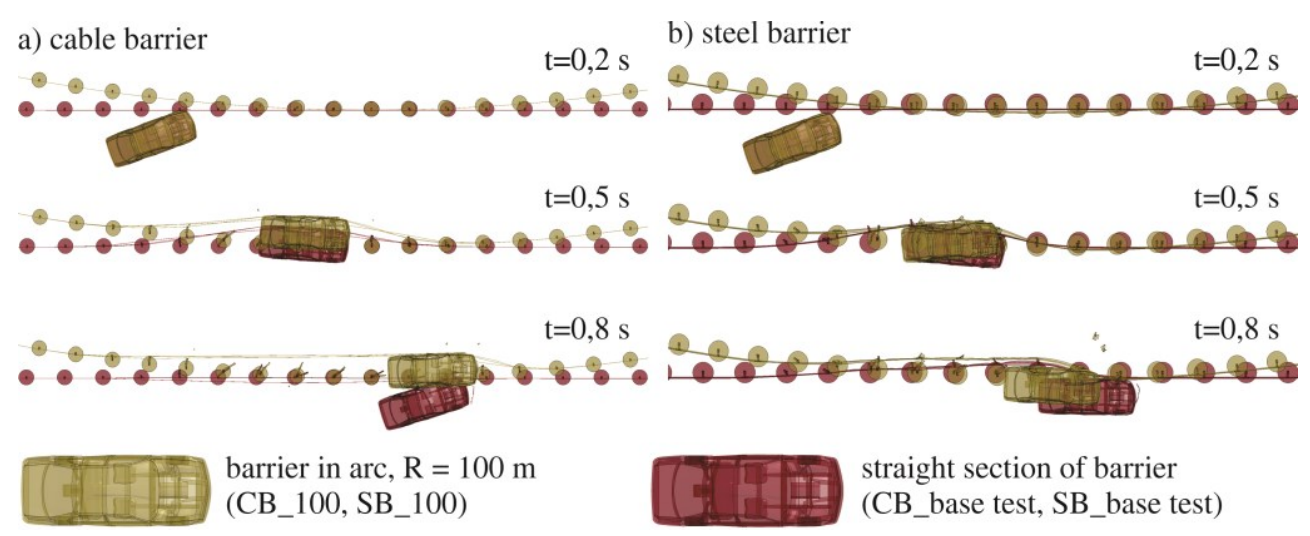

Fig. 3. Comparison of the tests for a curve $\mathrm{R}=100 \mathrm{~m}$ and straight section, a) cable barrier, b) steel barrier.

\section{Conclusion}

As elements of road infrastructure, horizontal curves generate road user hazards resulting from the dynamics and kinematics of moving vehicles. Horizontal curve design and maintenance require the right curve geometry and restraints to prevent errant vehicles. As we know from statistics, about $16 \%$ of all fatalities occur on horizontal curves. About $38 \%$ of all horizontal curve fatalities occurred as a result of the vehicle leaving the road and hitting an obstacle or rolling over away from the road. The data have identified a very serious problem and the need to continue research to model safety by including the parameters of vertical alignment. Road safety devices can be better selected using numerical crash tests. They complement test site results and deliver data on the effects of selected road and traffic parameters on the functionality of road safety equipment and ultimately promote effective solutions and better road safety.

This work was supported by the National Centre for Research and Development (NCBiR) and the General Directorate for National Roads and Motorways (GDDKiA) under the research project "Road Safety Equipment" (contract number DZP/RID-I-67/13/NCBR/2016). Calculations have been carried out at the Academic Computer Centre in Gdańsk, Gdańsk University of Technology. The BMW model was developed by Transpolis (formerly LIER), a French crash-test house and digital simulation office for road safety equipment.

\section{References}

1. R. Fuller, Towards a general theory of driver behaviour, Accid. Anal. Prev. 37 pp. 461-72 (2005). doi:10.1016/j.aap.2004.11.003

2. P. Larsson, S.W.A. Dekker, C. Tingvall, The need for a systems theory approach to road safety, Saf. Sci. 48 pp. 1167-1174 (2010). doi:10.1016/j.ssci.2009.10.006

3. D.W. Harwood, F.M. Council, E. Hauer, W.E. Hughes, A. Vogt, Prediction of the Expected Safety Performance of Rural Two-Lane Highways (Federal Highway Administration U.S. Department of Transportation, 2000)

4. Road protection score (RPS) method and pilot results (EuroRAP, 2002)

5. W. Kustra, K. Jamroz, M. Budzynski, Safety PL- A Support Tool for Road Safety Impact Assessment, Transp. Res. Procedia. 14 pp. 3456-3465 (2016). doi:10.1016/J.TRPRO.2016.05.308 
6. A. Fernandes, J. Neves, An approach to accidents modeling based on compounds road environments, Accid. Anal. Prev. 53 pp. 39-45 (2013). doi:10.1016/j.aap.2012.12.041

7. S. Cafiso, A. Di Graziano, G. Di Silvestro, G. La Cava, B. Persaud, Development of comprehensive accident models for two-lane rural highways using exposure, geometry, consistency and context variables, Accid. Anal. Prev. 42 pp. 1072-1079 (2010). doi:10.1016/j.aap.2009.12.015

8. J.N. Ivan, P.E. Garder, Z. Deng, C. Zhang, The effect of segment characteristics on the severity of head-on crashes on two-lane rural highways (University of Connecticut, University of Maine, 2006)

9. M. Garnowski, H. Manner, On factors related to car accidents on German Autobahn connectors, Accid. Anal. Prev. 43 pp. 1864-1871 (2011). doi:10.1016/J.AAP.2011.04.026

10. J. Lee, F. Mannering, Impact of roadside features on the frequency and severity of run-off-roadway accidents: an empirical analysis, Accid. Anal. Prev. 34 pp. 149-161 (2002). doi:10.1016/S0001-4575(01)00009-4

11. Accident modification factors (Federal Highway Administration, U.S. Department of Transportation, 2005)

12. C. Wang, M.A. Quddus, S.G. Ison, Predicting accident frequency at their severity levels and its application in site ranking using a two-stage mixed multivariate model, Accid. Anal. Prev. 43 pp. 1979-1990 (2011). doi:10.1016/J.AAP.2011.05.016

13. A. Jacob, R. Dhanya, M.V.L.R. Anjaneyulu, Geometric Design Consistency of Multiple Horizontal Curves on Two-lane Rural Highways, Procedia - Soc. Behav. Sci. 104 pp. 1068-1077 (2013). doi:10.1016/J.SBSPRO.2013.11.202

14. M.A. Abdel-Aty, A.E. Radwan, Modeling traffic accident occurrence and involvement, Accid. Anal. Prev. 32 pp. 633-642 (2000). doi:10.1016/S00014575(99)00094-9

15. M.F. Muhammad, H.J. Mohammed, Concrete road barriers subjected to impact loads: An overview, Lat. Am. J. Solids Struct. 12 pp. 1824-1858 (2015). doi:10.1590/167978251783

16. S. Mondal, Y. Lucet, W. Hare, Optimizing horizontal alignment of roads in a specified corridor, Comput. Oper. Res. 64 pp. 130-138 (2015). doi:10.1016/J.COR.2015.05.018

17. A Guide for Reducing Collisions on Horizontal Curves. NCHRP Report 500(7) (Transportation Research Board, Washington, D.C., 2004). doi:10.17226/13545

18. S. Othman, R. Thomson, G. Lannér, Safety Analysis of Horizontal Curves Using Real Traffic Data, J. Transp. Eng. 140 pp. 04014005 (2014). doi:10.1061/(ASCE)TE.19435436.0000626

19. C. Jurewicz, R. Excel, Application of a Crash-predictive Risk Assessment Model to Prioritise Road Safety Investment in Australia, Transp. Res. Procedia. 14 pp. 21012110 (2016). doi:10.1016/J.TRPRO.2016.05.225

20. G. Yannis, A. Dragomanovits, A. Laiou, T. Richter, S. Ruhl, F. La Torre, L. Domenichini, D. Graham, N. Karathodorou, H. Li, Use of Accident Prediction Models in Road Safety Management - An International Inquiry, Transp. Res. Procedia. 14 pp. 4257-4266 (2016). doi:10.1016/J.TRPRO.2016.05.397

21. T. Esposito, R. Mauro, F. Russo, G. Dell'Acqua, Speed prediction models for sustainable road safety management, Procedia - Soc. Behav. Sci. 20 pp. 568-576 (2011). doi:10.1016/J.SBSPRO.2011.08.063 
22. M. Klasztorny, K. Zielonka, D.B. Nycz, P. Posuniak, R. Romanowski, Experimental and simulation crash tests of the SP-05/2 barrier in the concave horizontal curve, in: XIV Sci. Tech. Conf. Comput. Technol. Eng., (2016)

23. R.P. Nasution, R.A. Siregar, K. Fuad, A.H. Adom, The Effect of ASI (Acceleration Severity Index) to Different Crash Velocities, in: Proc. Int. Conf. Appl. Des. Mech. Eng., pp. 11-13 (2009)

24. W. Borkowski, Z. Hryciów, P. Rybak, J. Wysocki, Analysis of the effectiveness of concrete protection barriers on the road curve, Mech. Rev. LXXI pp. 21-24 (2012)

25. D. Nycz, Modeling and numerical tests of crash tests of N2-W4-A class barriers on road curves, Military University of Technology, Warsaw, 2015

26. D. Marzougui, U. Mahadevaiah, F. Tahan, C.D. Kan, R. McGinnis, R. Powers, Guidance for selection, use and maintenance of cable barrier system. NCHRP Raport 711 (Transport Research Board, Washington, USA, 2012)

27. PN-EN 1317-1 Road restraint systems, Part 1: Terminology and general criteria for test methods, (2010)

28. PN-EN 1317-2 Road restraint systems, Part 2: Performance classes, impact test acceptance criteria and test methods for safety barriers (2010)

29. J.O. Hallquist, LS-DYNA Theory Manual (Livermore Software Technology Corporation, 2006) 